auxilliaries with little formal education. But we could never guarantee a 24-hour nursing presence and patients could count themselves fortunate if at any time there was one nurse for four patients.

Christian Medical Fellowship,

R K M SANDERS

London SE1 8XN

1 Sanders, R K M, et al, Lancet, 1977, 1, 974. akil, B J, et al, Proceedings of the Fourth International Conference on Tetanus, Dakar,

p 423. Lyon, Foundation Merieux, 1975 . Society of Tropical Medicine and Hygiene, 1969, 63, 746 .

\section{Prophylaxis of tetanus}

SIR,-I was interested in the article "Intensive care in tetanus" (26 May, p 1401) describing the history and treatment of 100 cases at Leeds General Infirmary during 1961-77.

It states that, of those patients who did seek medical attention for their injury, 25 were given tetanus toxoid and 21 prophylactic antibiotics, but none received antitetanus serum, either equine or human. During my 37 years of practice in a rural area I had to deal with a large number of wounds where it was necessary to provide prophylaxis against tetanus. I have always maintained that for patients who had not been previously immunised with tetanus toxoid it is not enough to treat them with toxoid or antibiotics at the time of injury but that they must have antiserum. I may say that in a long experience I have fortunately never had a case of anaphylaxis due to this procedure, although I have encountered mild reactions-mostly urticaria. I would add that I gave a minimum test dose in case of reaction, and then waited a quarter of an hour before giving the full dose.

I should be interested to hear other people's views on this matter as I know it is now common practice to give toxoid with or without an antibiotic to patients with wounds potentially infected with tetanus. Indeed I know of one case in my own practice, which occurred after I had retired, in which a patient who had not been previously immunised was given toxoid for a wound incurred in her garden and subsequently developed tetanus, from which she fortunately recovered in hospital.

Shere, Surrey

J F STENT

\section{Antibiotic-induced interstitial nephritis?}

SIR,-With reference to Dr C T Flynn's repudiations (16 June, $p 1628$ ) of the conclusions in our paper (5 May, p 1182), we would like to reinforce the following points.

Firstly, one of us (DJR) effectively managed all three episodes of acute renal failure in this patient and performed the renal biopsy following the administration of gentamicin. All the original renal biopsy material from 1974 has been re-examined and it confirms as stated the presence of acute interstitial nephritis temporally related to the administration of gentamicin. The subsequent rapid response to highdose intravenous methylprednisolone serves as confirmatory evidence.

Secondly, gentamicin levels were kept within recommended limits as documented. Gentamicin was first administered on 23 July 1974 in a dose of $80 \mathrm{mg}$ twice daily commensurate with the patient's renal function. Peak gentamicin levels were if anything low at $4.0 \mu \mathrm{g} / \mathrm{ml}$ (24 July) and $4.5 \mu \mathrm{g} / \mathrm{ml}$ (25 July). Treatment was stopped on 26 July because of the decline in renal function and was not given on this date.

Thirdly, the remarks by Dr Flynn with reference to co-trimoxazole serve to demonstrate why so many cases of drug-induced acute renal failure probably go unrecognised. This patient had been repeatedly told not to take any antibiotic without prior consultation. The history of co-trimoxazole ingestion was, in fact, obtained from his wife, for whom the drug had been prescribed. As he was so ill initially, confirmation was only obtained from the patient during his recovery. There was no question of reluctance to admit taking the drug, merely embarrassment at his folly. We can only emphasise the importance of careful and repeated history taking. How many of us have toiled for years to obtain a true drug history from patients with analgesic nephropathy?

The object of our short report was to record not only that gentamicin can cause acute interstitial nephritis but also that multiple episodes due to different antibiotics can occur in the same patient. It was also our intention to underline the importance of early renal biopsy and high-dose steroid therapy in these cases.

D SALTISSI

C D PUSEY DAVID J RAINFORD

Department of Renal Medicine, Princess Mary's RAF Hospital,
Aylesbury, Bucks HP22 5 PS

\section{Collaborating with the pharmaceutical industry}

SIR,-I write to support the point of view expressed by Dr B N C Prichard (17 March, $p$ 747) on the relationship between the pharmaceutical industry and university departments such as haematology or medicine.

It is likely that co-operation is to the mutual benefit of both parties and, as far as I am aware, those of us following this practice have seldom transgressed the important considerations of propriety or objectivity in joint investigation. It seems to me, as to Dr Prichard, that the critical evaluation of a new product is often best carried out in a department where particular interest and expertise is already available and where objectivity is therefore likely to be at its highest. In the best traditions of scientific medicine neither the investigator nor any reputable company would wish that anything but the truth emerge from such collaboration. Certainly my experience has been that free interchange with scientific officers in company research establishments may improve trial design, substantially contribute to critical analysis of data, and clarify the presentation of results.

It has been of particular interest to observe that the number of collaborative efforts are steadily increasing: many individuals and departments who previously resisted such associations appear to be shifting their position. It would be my hope that this reflects the ever-increasing acceptance of the fact that association with the pharmaceutical industry in areas of obvious common interest does not automatically bias results. In the final analysis the viability of this desirable interaction between academic medicine and colleagues in drug development comes down to the scientific reputation of the two parties and, from my own experience, is a collaboration to be strongly encouraged and further developed.

Department of Haematology,

University of Cape Town

Cape, South Africa

\section{Proteinuria at high altitude}

SIR,-Drs A R Bradwell and J Delamere (21 April, p 1083) questioned the significance of altitude in producing proteinuria and thought that my investigation ${ }^{1}$ did not distinguish between exercise and altitude as causes.

Recently, four fit and experienced climbers made ascents of three mountains of heights of 3400 to $3600 \mathrm{~m}$ in the French Alps at successive two-day intervals. On each occasion urine was tested with the Multistix strip test for protein concentration in samples taken immediately after the climb and also 24 hours later after discarding the first morning urine. Out of the total of 12 urine samples tested immediately after the climb there was a trace of albumin in four specimens and $30 \mathrm{mg}$ in two specimens. Twenty-four hours later there was a trace of protein only in four specimens; no protein was detected in the remaining six specimens.

Thus within the limits of this investigation exercise produced little proteinuria and only traces were present 24 hours later. This is in contrast to the mean urine concentration of protein of over $100 \mathrm{mg} / 100 \mathrm{ml}$ taken 24 hours after climbs of up to $5890 \mathrm{~m}$ in similarly fit climbers. ${ }^{1}$ Thus altitude does seem a significant factor in the production of proteinuria.

A Pines

East Herts Hospital,
Hertford SG13 7HU

Pines, A, British fournal of Diseases of the Chest, 1978, 72, 196

Renal enzyme and protein excretion after induction of a diuresis

SIR,-Different results have been recently reported in the $B M \mathcal{F}^{12}$ on .urinary $N$-acetyl$\beta$-glucosaminidase (NAG) excretion following $80 \mathrm{mg}$ oral frusemide. In the first letter some doubts were also being raised on the use of urinary enzyme determinations as sensitive indicators of renal damage after drug administration.

$\mathrm{We}^{3}$ have investigated in eight healthy volunteers the urinary excretion of $\alpha$-glucosidase lysozyme and, $\beta_{2}$-microglobulin after induction of a diuresis by administering tap water $(500 \mathrm{ml}$ by mouth in 30 minutes in the first day), frusemide (20 mg intravenously on the fifth day), and $20 \%$ mannitol $(500 \mathrm{ml}$ intravenously in 60 minutes on the ninth day). Urine samples were collected for two nights after mannitol administration. $\alpha$-Glucosidase $^{4-6}$ is a lysosomal enzyme, which is present as NAG in tubular cells and absent in plasma and which increases in urine after a tubular damage. Lysozyme and $\beta_{2}$-microglobulin are microproteins, whose increase in urine suggests a reduced tubular reabsorption of filtered microproteins ("tubular proteinuria")

Our results ${ }^{3}$ do not show any significant effect of water, frusemide, and mannitol administration on $\alpha$-glucosidase excretion. Urinary lysozyme and $\beta_{2}$-microglobulin excretion, however, was increased by diuresis. The increase was significant for lysozyme after water and for $\beta_{2}$-microglobulin after frusemide administration. A more striking effect of water, frusemide, and mannitol administration on enzymuria and proteinuria was observed in 